\title{
Обнаружение сильного влияния вариаций состава на низкотемпературное магнитное упорядочение почти стехиометрических сплавов $\mathrm{Fe}-\mathrm{V}-\mathrm{Al}$
}

\author{
(C) T.E. Говоркова ${ }^{1}$, А.Т. Лончаков ${ }^{1}$, В.В. Марченков ${ }^{1,2}$, \\ В.И. Окулов ${ }^{1}$, С.М. Подгорных ${ }^{1}$, В.С. Гавико ${ }^{1}$, \\ С.М. Емельянова ${ }^{1}$
}

${ }^{1}$ Институт фризики металлов им. М.Н. Михеева УрО РАН, Екатеринбург 2 Уральский фредеральный университет, Екатеринбург

E-mail: govorkova@imp.uran.ru

Поступило в Редакцию 17 июня 2016 г.

Исследовано магнитное состояние сплава $\mathrm{Fe}-\mathrm{V}-\mathrm{Al}$ с составами вблизи стехиометрии ( $\left.\mathrm{Fe}_{2} \mathrm{VAl}\right)$ при изменении содержания атомов как переходных элементов, так и алюминия. Изучены обнаруженные впервые эффекты сильного качественного изменения магнитных свойств, наблюдавшиеся при малых вариациях состава. Наиболее важный результат - обнаружение ферромагнитного упорядочения с относительно высокой $(\sim 50 \mathrm{~K})$ температурой Кюри для сплава, в котором атомы Al замещают в решетке атомы V, а содержание Fe отвечает стехиометрическому составу.

Сплавы $\mathrm{Fe}_{2+x} \mathrm{~V}_{1-x} \mathrm{Al}$ с составами, близкими к стехиометрии, могут обладать одновременно спонтанной спиновой поляризацией носителей заряда и полупроводниковыми свойствами. В связи с этим представляет интерес детальное изучение изменений магнитного состояния данных сплавов при вариации состава в небольшом интервале ( 10 at.\%) вблизи стехиометрического. Такого рода исследования проводились ранее для сплавов, обогашенных по атомам $\mathrm{Fe}$ или $\mathrm{V}[1,2]$. Было установлено, что в сплавах $\mathrm{Fe}_{2+x} \mathrm{~V}_{1-x} \mathrm{Al}$ при $x \geqslant 0.05$ наблюдается переход в ферромагнитное состояние. Показано, что температура Кюри и величина спонтанной намагниченности возрастают с ростом содержания железа [1]. Установлено, что сплавы, обогащенные ванадием, являются парамагнитными с низкой концентрацией магнитных дефектов [2]. Однако для разработки обоснованного описания природы маг- 
нетизма данных объектов необходимы более детальные исследования совокупности физических свойств для разных составов. К этому кругу исследований относится содержание настоящей работы. Нами проведены экспериментальные исследования магнитного состояния сплава $\mathrm{Fe}_{2+x} \mathrm{~V}_{1-x} \mathrm{Al}$ с различным содержанием вблизи стехиометрического состава не только атомов переходных элементов (Fe, V), но и атомов алюминия.

Сплавы $\mathrm{Fe}-\mathrm{V}-\mathrm{Al}$ разных составов были выплавлены в индукционной печи в атмосфере очищенного аргона с трехкратным переплавом для получения лучшей однородности и затем охлаждены вместе с печью. Атомное содержание элементов контролировалось с помощью растрового электронного микроскопа Inspect F (FEI Company), оснащенного приставкой рентгеновского микроанализа EDAX с относительной погрешностью не более 1 at.\%. По результатам химического анализа были выбраны четыре образца, близкие по составу к стехиометрическому: образец $1-\mathrm{Fe}_{1.87} \mathrm{~V}_{1.1} \mathrm{Al}_{1.03}, 2-\mathrm{Fe}_{1.76} \mathrm{~V}_{1.19} \mathrm{Al}_{1.05}, 3-$ $\mathrm{Fe}_{2.21} \mathrm{~V}_{0.92} \mathrm{Al}_{0.87}, 4-\mathrm{Fe}_{1.99} \mathrm{~V}_{0.89} \mathrm{Al}_{1.12}$. Рентгеноструктурные исследования показали, что все образцы являются однофазными и обладают упорядоченной структурой по типу $L 2{ }_{1}$.

Измерения намагниченности $M$ и начальной магнитной восприимчивости $\chi_{A C}$ были проведены на СКВИД-магнитометре MPMS-5-XL (Quantum Design Co.) в температурном интервале $1.8-300 \mathrm{~K}$ в магнитном поле до $10 \mathrm{kOe}$. Выбранные для измерений образцы можно разделить на две группы, характеризуемые повышенным (образцы 1, 2) и пониженным (образцы 3,4 ) содержанием атомов V относительно содержания $\mathrm{Fe}$ в стехиометрическом составе. При таком разделении анализ свойств образцов 1 и 2 позволяет изучить модификацию магнетизма сплава при замене атомов железа на атомы ванадия. С другой стороны, анализируя магнитные свойства образцов 3 и 4, необходимо определить роль атомов железа в магнетизме совокупности исследуемых сплавов. Рассматривая различие магнитного состояния образцов этой группы, можно получить данные о роли атомов алюминия.

Результаты магнитных измерений представлены на рис. 1-3. Из рис. $1, a$ видно, что магнитная восприимчивость $\chi(T)$ для образцов 1 и 2 близка по величине и при высоких температурах отвечает закону Кюри. Парамагнитный характер данных сплавов подтверждается экспериментами по начальной восприимчивости $\chi_{A C}$ (вставка к рис. 2). Этот факт свидетельствует об отсутствии спонтанной намагниченности

Письма в ЖТФ, 2016, том 42, вып. 22 

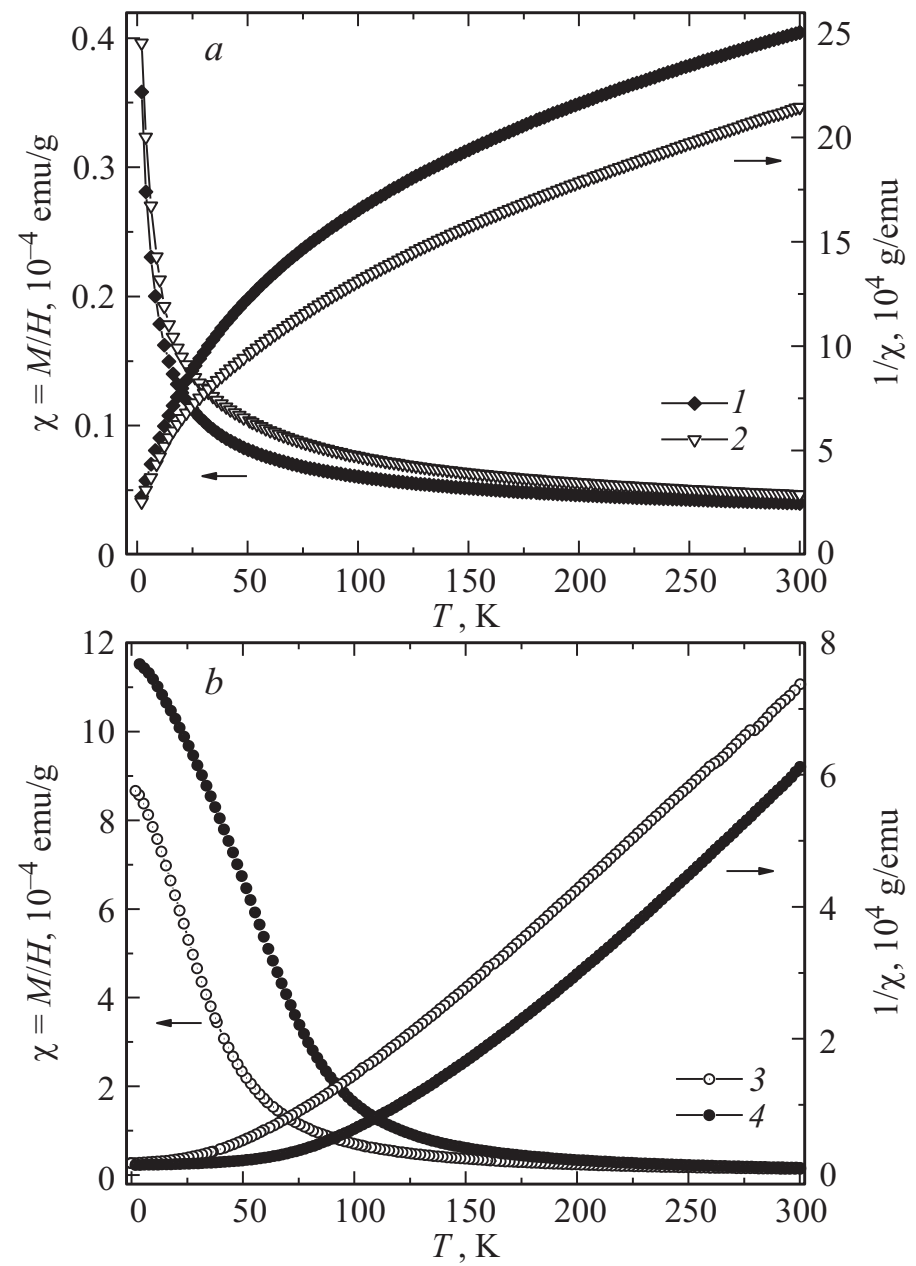

Рис. 1. Температурные зависимости магнитной восприимчивости $\chi$ и зависимости $\chi^{-1}(T)$ в магнитном поле $10 \mathrm{kOe}$ для образцов $1,2(a)$ и $3,4(b)$. Номера кривых на этом и других рисунках совпадают с номерами образцов в тексте.

в сплавах с небольшим избыточным содержанием ванадия. Из анализа экспериментальных зависимостей $\chi(T)$ определены эффективные маг-

4* Письма в ЖТФ, 2016, том 42, вып. 22 


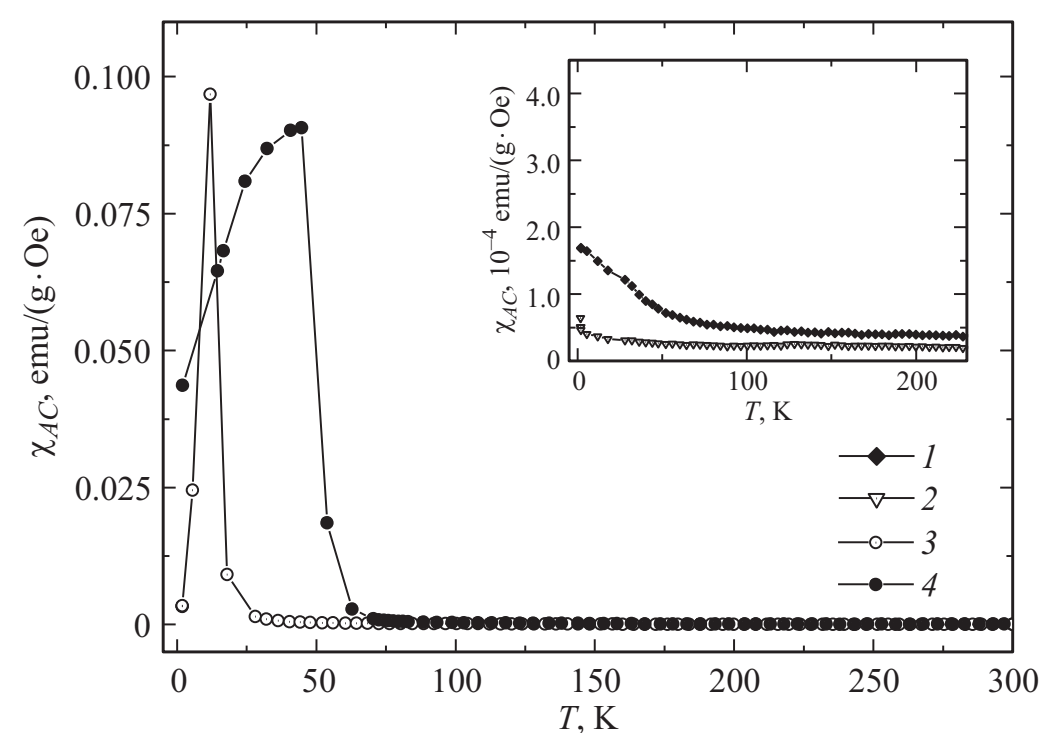

Рис. 2. Температурные зависимости начальной магнитной восприимчивости $\chi_{A C}$ для образцов 3,4 . На вставке: зависимости $\chi_{A C}(T)$ для образцов 1,2 .

нитные моменты локализованных спинов атомов железа $\mu_{p}=0.24 \mu_{B} / \mathrm{Fe}$ и $\mu_{p}=0.32 \mu_{B} / \mathrm{Fe}$ для образцов 1 и 2 соответственно.

Совершенно иные магнитные свойства демонстрируют образцы 3 и 4. Температурные зависимости восприимчивости $\chi(T)$ данных сплавов (рис. $1, b$ ) описываются законом Кюри-Вейсса в высокотемпературной области, а поведение начальной восприимчивости $\chi_{A C}(T)$ с характерными ярко выраженными максимумами при $T \leqslant 60 \mathrm{~K}$ (рис. 2) свидетельствует о переходах в магнитоупорядоченное состояние. Наличие ферромагнетизма подтверждается также наблюдением области насыщения на кривых намагничивания $M(H)$ (рис. 3). Если связывать намагниченность только с атомами железа, то по найденным из экспериментальных данных значениям констант Кюри определяются следующие значения эффективных моментов: $\mu_{p}=0.91 \mu_{B} / \mathrm{Fe}$ и $\mu_{p}=1.01 \mu_{B} / \mathrm{Fe}$ для образцов 3 и 4, соответственно. Сравнительно сильный спонтанный магнетизм проявляет образец 4, содержание железа в котором практически отвечает стехиометрическому составу. Для этого образца парамагнитная темпе-

Письма в ЖТФ, 2016, том 42, вып. 22 


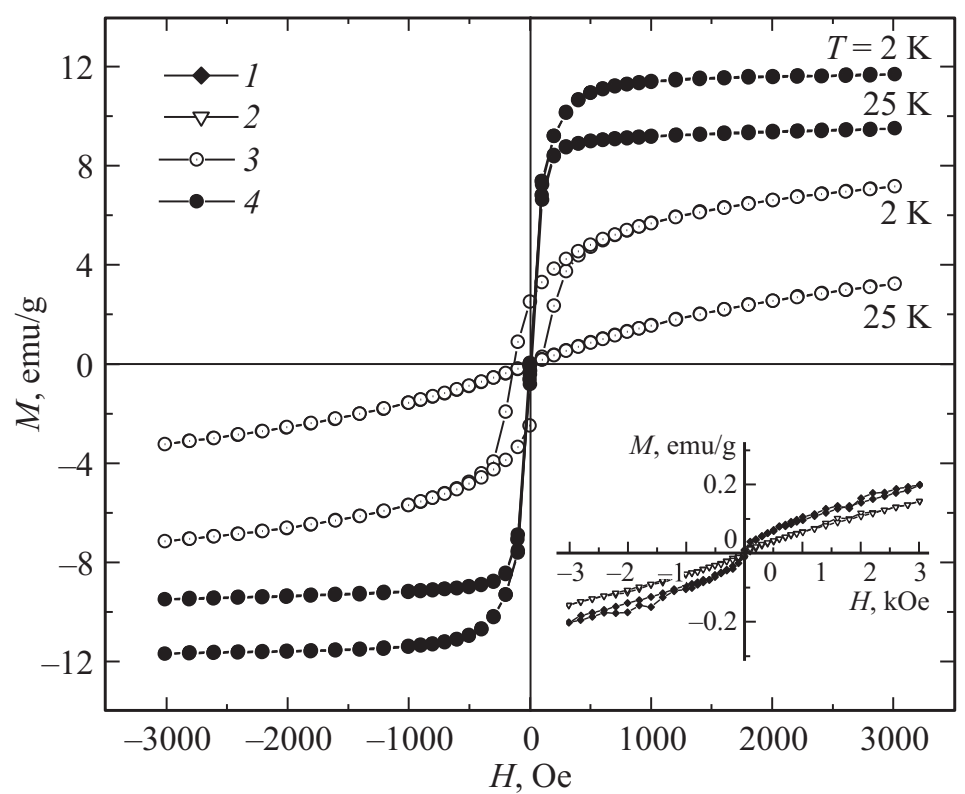

Рис. 3. Зависимости удельной намагниченности от магнитного поля $M(H)$ при фиксированных температурах для образцов 3,4 . На вставке: зависимости $M(H)$ для образцов 1,2 при $T=2 \mathrm{~K}$.

ратура Кюри $\Theta$, характеризующая энергию обменного взаимодействия, близка к $100 \mathrm{~K}$, тогда как для образца 3 значение $\Theta \approx 54 \mathrm{~K}$. Значительно отличаются и температура перехода в ферромагнитное состояние $T_{C}$, полученная из зависимостей $\chi_{A C}\left(T_{C} \approx 12 \mathrm{~K}\right.$ для образца 3 и $T_{C} \approx 45 \mathrm{~K}$ для образца 4), а также значение спонтанного магнитного момента атомов железа $\left(\mu_{S}=0.1 \mu_{B} / \mathrm{Fe}\right.$ для образца 3 и $\mu_{S}=0.18 \mu_{B} / \mathrm{Fe}$ для образца 4 ), рассчитанное из намагниченности насыщения при $T=2 \mathrm{~K}$ (рис. 3).

Характеризуя в целом явление спонтанного намагничения, обнаруженного в образцах 3 и 4, можно заключить, что основное различие этого явления в исследованных сплавах происходит из-за разной интенсивности эффективного обменного взаимодействия, обеспечивающего спиновое упорядочение. Фундаментом для описания упомянутых ме-

Письма в ЖТФ, 2016, том 42, вып. 22 
ханизмов упорядочения можно считать модель коллективизированных электронов в общем ее виде, отражающем реальную электронную структуру. Предпосылкой для этого может служить хорошая проводимость сплавов, компонентами которых являются типичные металлы, а также обнаруженный нами недавно аномальный эффект Холла в сплаве, обогащенном алюминием [3]. В рамках такой модели можно считать, что в образце 4 магнитные атомы Fe располагаются в кристаллической ячейке в основном так же, как в кристалле стехиометрического состава, и связаны взаимодействиями, близкими к тем, которые существуют в почти идеальном кристалле. Что касается образца 3, то в нем, в силу избытка атомов $\mathrm{Fe}$, преобладает неупорядоченное расположение магнитных атомов, разрушающее связи идеального кристалла. Поэтому образец 3 аналогичен неупорядоченному сплаву, обладающему слабым механизмом упорядочения. Таким образом, незначительно изменяя состав сплава $\mathrm{Fe}_{2+x} \mathrm{~V}_{1-x} \mathrm{Al}$ (т.е. содержание атомов $\mathrm{Al}$ относительно содержания атомов Fe при сохранении обеднения по атомам V) мы получили объекты, существенно различные по магнитному состоянию.

Для описания механизма упорядочения в образце 4 возможно применение конкретной модели, исходящей из представлений физики магнитных соединений. В этой модели учитывается, что некоторые атомы Fe находятся в немагнитном тетраэдрическом окружении. Избыточные атомы Al занимают октаэдрические положения атомов V в первой координационной сфере ионов $\mathrm{Fe}^{3+}$. Из-за разницы ионных радиусов $\mathrm{Al}^{3+}(0.57 \AA)$ и $\mathrm{V}^{3+}(0.67 \AA)$ локальная тетраэдрическая симметрия ионов $\mathrm{Fe}^{3+}$ нарушается и можно предположить, что в основном состоянии атомов железа возникают локализованные спины, и при этом образец 4 оказывается не однофазным, а состоит из магнитных кластеров типа $\mathrm{FeAl}_{y}$, встроенных в матрицу $\mathrm{Fe}_{2} \mathrm{VAl}$. В рамках этой модели, наряду с обменным взаимодействием локальных спинов кластеров через свободные носители, существует обменное взаимодействие локальных спинов кластеров через спиновые флуктуации. В подобной модели, использованной в работе [4], показана возможность увеличения $T_{C}$. Но для обоснования такой модели в нашем сплаве требуется прямое обнаружение предсказываемых кластеров, и она вряд ли может быть согласована с наблюдаемым значением константы Кюри в магнитной восприимчивости, а также с самим фактом возникновения достаточного количества кластеров в условиях малого отклонения от стехиометрии. Однако и другие модели, описывающие механизм магнитного упорядо-

Письма в ЖТФ, 2016, том 42, вып. 22 
чения в исследуемых сплавах, требуют обоснования, т.е. продолжения экспериментальных и теоретических исследований, началом которых могут послужить результаты данной работы.

В настоящей работе поставлена задача более детально изучить магнитные свойства сплава $\mathrm{Fe}-\mathrm{V}-\mathrm{Al}$ с составами, близкими к стехиометрии. В результате анализа экспериментальных данных по намагниченности и магнитной восприимчивости сформулированы выводы относительно сильного качественного изменения магнитных свойств сплава $\mathrm{Fe}-\mathrm{V}-\mathrm{Al}$ при малых вариациях состава. Впервые показано, что при фиксированном уменьшенном содержании ванадия характер магнитного упорядочения сильно изменяется в зависимости от соотношения относительного содержания атомов Fe и Al. B этом аспекте к полученным важным результатам относится обнаружение ферромагнитного сплава с температурой Кюри, превышающей $50 \mathrm{~K}$, и характерных особенностей магнитного упорядочения сплава, обедненного алюминием.

Работа выполнена в рамках государственного задания ФАНО России (тема „Электрон“, № 01201463326) при частичной поддержке гранта РФФИ (проект № 14-02-01238), молодежного гранта РФФИ (проект № 16-32-00072), программы фундаментальных исследований УрО РАН (проект № 15-17-2-32) и Правительства Российской Федерации (контракт № 02.A03.21.0006).

\section{Список литературы}

[1] Kanamota T., Sasaki T., Hoshi T. et al. // J. Alloys Compds. 2001. V. 317-318. P. 390.

[2] Ishikawa F., Fukuda K., Kawase K. et al. // J. Magn. Magn. Mater. 2007. V. 310. P. 616.

[3] Лончаков А.Т., Марченков В.В., Окулов В.И. и др. // ФНТ. 2016. Т. 42. № 3. C. 297-299. [Lonchakov A.T., Marchenkov V.V., Okulov V.I. et al. // Low Temp. Phys. 2016. V. 42. P. 230-231.]

[4] Николаев С.Н., Аронзон Б.А., Рыльков В.В. и др. // Письма в ЖЭТФ. 2009. T. 89. № 12. C. 707-712. [Nikolaev S.N., Aronzon B.A., Ryl'kov V.V. et al. // JETP Lett. 2009. V. 89. P. 603-607.]

Письма в ЖТФ, 2016, том 42, вып. 22 